East African Medical Journal Vol. 87 No. 4 April 2010

DIAGNOSTIC UTILITY OF FINE-NEEDLE ASPIRATION CYTOLOGY IN THE MANAGEMENT OF LIVER DISEASE IN A DISTRICT HOSPITAL

T. L. Shiramba, MSc, DIC, CBiolSc, FIBMS, Clinical Cytologist, H. A. Lodenyo, MBChB, MMed, Cert. Gastroenterology (Wits. RSA), Senior Research Officer, J. M. Kabanga, HND, Chief Technologist and J. K Kuria, HND, Senior Technologist, Centre for Clinical Research, Kenya Medical Research Institute, P. O. Box $20778 \neg 00200$, Nairobi, Kenya

Request for reprints: Dr. H. A. Lodenyo, Centre for Clinical Research, Kenya Medical Research Institute, P. O. Box 20778 - 00100, Nairobi, Kenya

\title{
DIAGNOSTIC UTILITY OF FINE-NEEDLE ASPIRATION CYTOLOGY IN THE MANAGEMENT OF LIVER DISEASE IN A DISTRICT HOSPITAL
}

\author{
T. L. SHIRAMBA, H.A. LODENYO, J.M. KABANGA and J. K. KURIA
}

\begin{abstract}
Background: Fine needle aspiration (FNA) cytology is a cost effective technique of obtaining cellular specimens for diagnoses. It has many advantages over large needle core biopsies that makes it quite suitable for outpatient department and institutions without facilities for histopathology diagnosis. Any site of the body can be sampled with FNA technique.

Objective: To assess the diagnostic utility of fine needle aspiration cytology technique in management of patients with liver disease in resource limited settings.

Design: Prospective cross sectional study.

Setting: Patient evaluation and FNA aspiration were done in Murang'a and Machakos district hospitals and specimen staining and microscopy were done in Centre for Clinical Research, Kenya Medical Research Institute.

Subjects: Patients who were suspected to have liver disease were referred to the medical outpatient clinics in Murang'a and Machakos district hospitals for evaluation. In addition those on the medical wards in the two hospitals who were suspected to have liver disease were also evaluated.

Interventions: The patients with liver disease were identified after physical and abdominal ultrasound examination. Those with hepatomegaly were selected for the study. Liver fine needle aspiration was done using 21 gauge fine needle attached to a $10 \mathrm{ml}$ syringe. Focal lesions were targeted as much as possible. Thin smears of specimens obtained were spread onto microscope slides which were then dropped into $95 \%$ ethanol and left for $30 \mathrm{~min}$ in order to fix the material. The slides were then removed, dried and transported to KEMRI where they were stained with Papanicolaou stain then evaluated on the light microscope.

Results: One hundred and twenty patients with suspected liver disease were evaluated in the two hospitals; 70 in Machakos and 50 in Murang'a. Fifty patients were identified to have liver disease and fine needle aspiration done aseptically. Twenty one $(42 \%)$ of the 50 patients had malignant cells; $15(30 \%)$ of the 50 patients had necrotic material aspirates $2(4 \%)$ shoved fatty changes later showed to be liver cirrhosis; $11(22 \%)$ showed normal hepatocytes.

Conclusion: The results support the diagnostic utility of FNA cytology in the management of liver disease, especially in rural setting.
\end{abstract}

\section{INTRODUCTION}

Liver diseases, particularly hepatocellularcarcinoma, are common in Kenya. Resources for needle biopsy with subsequent histological diagnoses are not available in most district hospitals. Fine-needle aspiration (FNA) and cytology of aspirated cellular material is a cost effective technique of diagnosis that is easy to use in smaller health facilities (1-4). In many centres, FNA has largely replaced conventional large needle core biopsy in the diagnosis of focal lesions in the liver (1-7). It has the advantage of less discomfort, very low risk of complications, hospitalisation of patient not necessary and enables a quick decision in options for clinical management (1-4). Its additional advantage is that it can be repeated from different sites until a satisfactory sample is obtained, without undue risks to the patient $(1,7)$. Use of imaging techniques make possible sampling of lesions, which may be inaccessible by other sampling methods, thereby 
making possible a tissue diagnosis in patients whose clinical conditions preclude other forms of obtaining specimens for investigation. Repeating of FNA from different sites has been reported to increase diagnostic sensitivity to over $90 \%$ (1-3).

In the evaluation of liver disease, the main indications for FNA cytology are single or multiple focal abnormalities demonstrated by palpation, CT scan or by ultrasonography (4).

The aim of this study was to test the utility of FNA cytology in excluding malignant disease of the liver at district hospitals, where histopathology facilities are not established. The accuracy of FNA cytology in the specific diagnosis of primary hepatocecullar carcinoma has been reported to increase to over $93 \%$ when combined with cell blocks $(5,6)$. In this study only smears were used.

\section{MATERIALS AND METHODS}

Patients with suspected liver disease visiting Murang'a and Machakos District Hospitals were evaluated and those with nodular hepatomegally were indentified for study. All the patients evaluated had right upper abdominal complaint and all had hepatomegally. The lesions were located by palpation or ultrasonography. Focal lesions were aspirated by transcutaneous fine needle aspiration (FNA) using a $10 \mathrm{ml}$ syringe and 21 gauge $1 \frac{1}{2}$ inch length needle. The cellular material aspirated was dropped onto a microscope slide, spread thinly and then immediately fixed while still wet in 95\% ethanol for 30 minutes.

The fixed smears were then air-dried, packed in slide-mailers and transported to the cytology laboratory at KEMRI in Nairobi. The fixed smears were stained by the Papanicolaou technique and interpreted on a light microscope by a cytologist.

\section{RESULTS}

Fifty patients were evaluated. Twenty one of the 50 (42\%) specimens had malignant cells; fifteen of the 50 $(30 \%)$ had necrotic cells; two of the $50(4 \%)$ had fatty change; one of the $50(2 \%)$ had reactive cell changes later confirmed to be cirrhosis on histology, and 11 of the $50(22 \%)$ showed normal hepatocytes.

Table 1

Cytologic diagnoses $(n=50)$

\begin{tabular}{llc}
\hline Diagnosis & No. & $(\%)$ \\
\hline Hepatocellular carcinoma & 21 & 42 \\
${ }^{*}$ Necrosis & 15 & 30 \\
Fatty change & 2 & 4 \\
Reactive cell changes & 1 & 2 \\
Normal hepatocytes & 11 & 22 \\
\hline
\end{tabular}

*Malignancy could not be excluded in the cases of necrosis.

Figure 1

Liver aspirate showing ductal carcinoma in situ, cribriform type. Large monolayered sheet of uniform epithelial cells with rounded spaces Pap. Stain $x 40$.

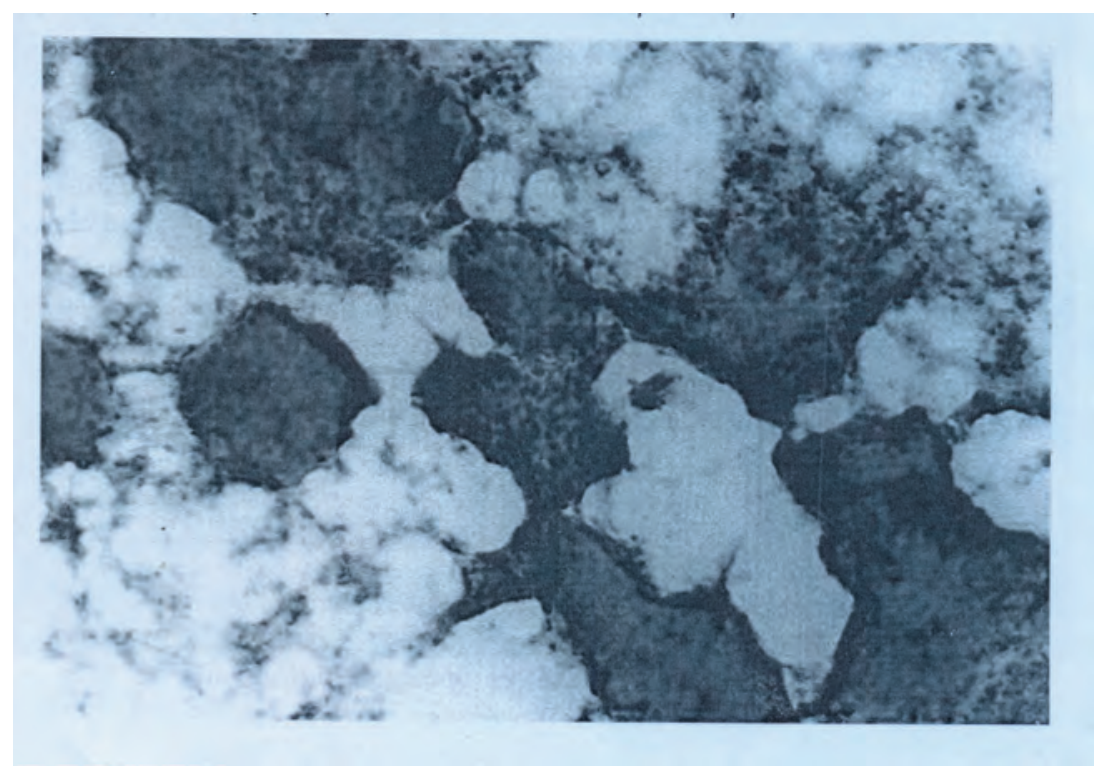


Figure 2

Papillary clusters of pleomorphic malignant cells from a liver aspirate. Pap. Stain $x 40$

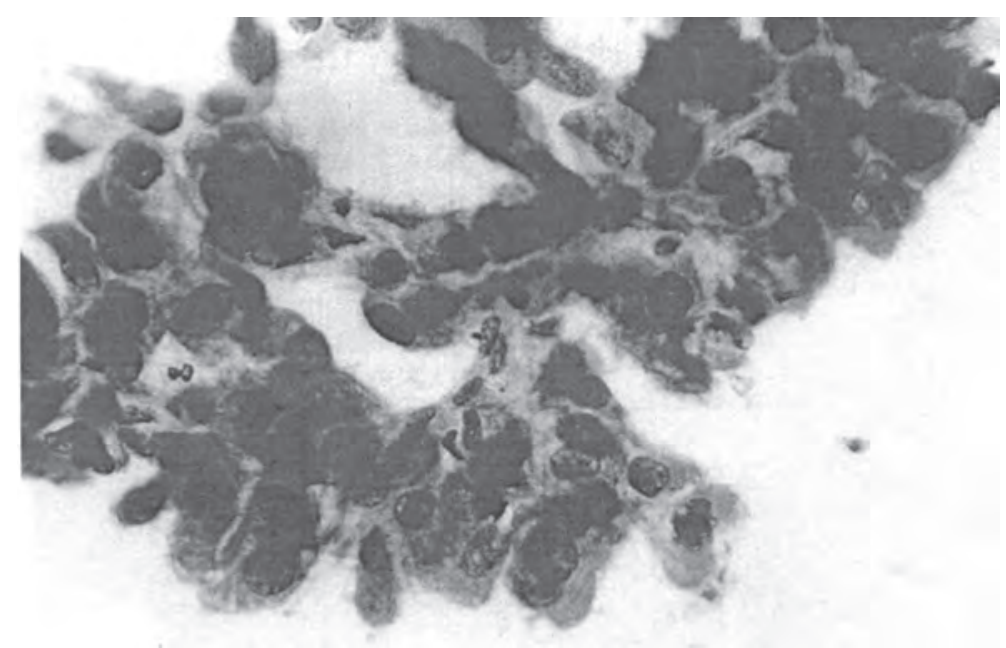

Figure 3

Dyshesive, pleomorphic malignant cells exhibiting coarse chromatin and prominent nucleoli. Note a cluster of cholangiocytes with small hyperchromatic nuclei at the top of the photomicrograph. Pap. Stain. $x 40$

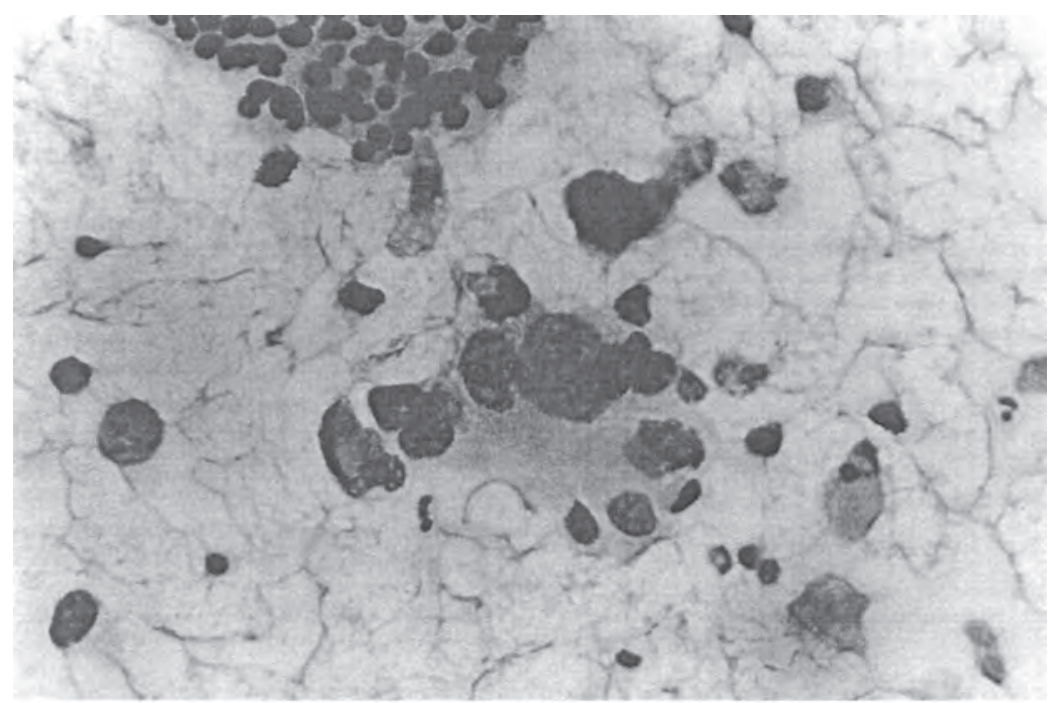

Figure 4

Necrosis of liver cells from an aspirate exhibiting degenerative nuclei whose cytoplasmic borders cannot be descerned surrounded by erythrocytes. Pap. Stain. $x 40$

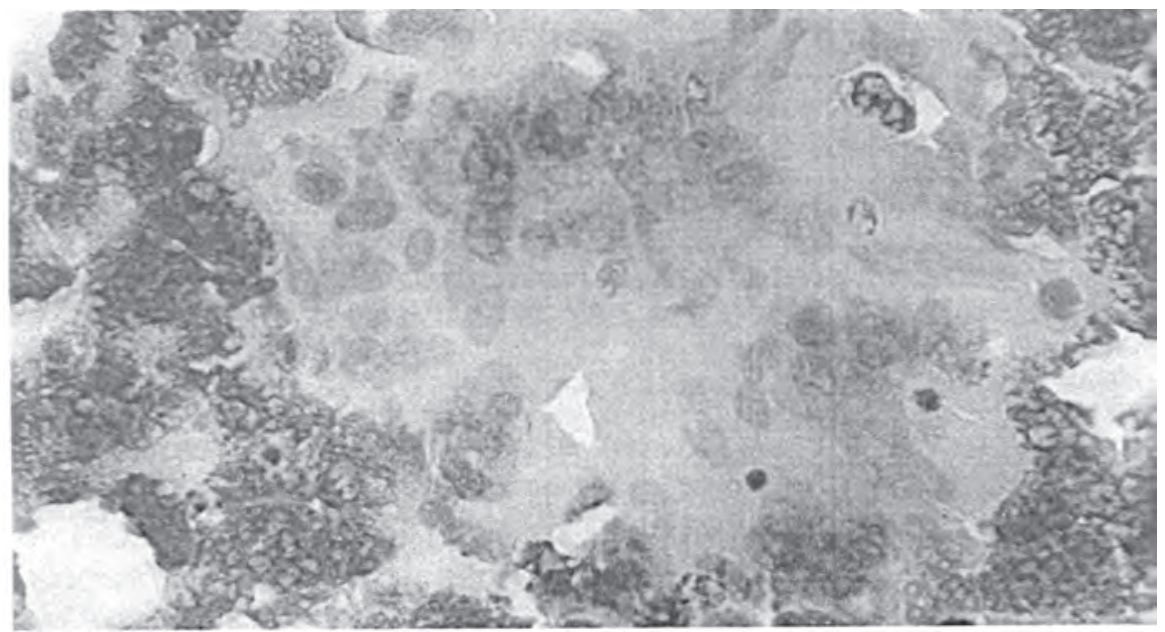




\section{DISCUSSION}

Diagnosis is an essential component of the management of any disease. FNA cytology established diagnoses on which the management of the 50 cases of liver disease were based: 21 hepatocellular carcinomas, 15 cases of necrotic liver, 2 cases of fatty change, 1 case of reactive hepatocytes and 11 normal livers. Toget these diagnoses on tissue biopsies would have required many times the resources used for FNA cytology.

\section{CONCLUSIONS}

Diagnostic utility of FN A cytology is high, especially when the lesions are precisely identified clinically and augmented by liver ultrasound. It is less invasive, and can be done as an outpatient procedure. Clinical management options in these patients were made based on the cytological diagnosis. The results supported the diagnostic utility of FNA cytology in the management of liver disease, especially in institutions without histopathology facilities.

\section{REFERENCES}

1. Orell, S. R. Sterrett, G. F., Walters, M. N. and Whitaker D. Manual and Atlas of Fine-Needle Aspiration Cytology. Second edition, Churchill Livingstone. 1992: 217-266.

2. Hubscher, S. G. and Young, J. A., Liver, In: Young, J. A. Editor. Fine-Needle Aspiration Cytopathology. Blackwell Scientific Publications. 1993: 134 - 151.

3. McKee, G. T. Cytopathology, Mosby - Wolfe Publishers; 1997: 258 - 264.

4. Ducatman, B. S. Fine-Needle Aspiration of the Liver and Pancreas. In: Atkinson B. F., Atlas of Diagnostic Cytopathology, W. B. Saunders Company, Philadelphia Pensylvania, 1992: 317 - 350.

5. Coleman, D. V. and Chapman, P. A. Editors: Clinical Cytopathology. Butterworth and Company (Publishers) Ltd. 1989: 359 - 362.

6. Waters, E. and Amstrong, J. Disorders of the liver. In: Gray E., Ed. Diagnostic Cytopathology. Edinburgh, Churchill Livingstone. 1995: 353 - 401.

7. Chandra Grubb. Diagnostic cytopathology, a text and colour atlas. Churchill Livingstone. 1988: 156 - 164. 